\title{
Youtube Motivations of University Students in The Context of Uses and Gratifications Approach
}

\author{
Köktener A. ${ }^{1}$ \\ Algül A. ${ }^{2}$
}

${ }^{1}$ Aysun KÖKTENER, İstanbul Aydın University, (Turkey)
e-mail: aysunkoktener@yahoo.com
2 And ALGÜL, İstanbul Aydın University, (Turkey)
e-mail: algul_a@yahoo.com

Abstract

Social media platforms have begun to be quite widely used as alternatives of the conventional media among the young in the recent years. The ratings and number of users of YouTube - a social media platform established in 2005 for image recording, storage, and sharing - worldwide and in Turkey have increased depending on the change in the mobile use habits as well as on the flourishing of smartphones. It is seen that the use of YouTube has become widespread particularly among the young in the sense of reaching information and of social interaction as well as for reputation acquisition, to become famous, and for entertainment. In this context, a survey was carried out in December 2017 to reveal the motivations of some 579 university students for use by employing the method of random sampling. As a result of the research, it was discovered that the university students used YouTube on each day of the week and for an hour to 3 hours daily to acquire information and reach alternative information, for access to alternative news broadcasting, and to obtain economic and social utility most and accessed YouTube largely by means of a laptop.

Keywords: YouTube, Uses and Gratifications Approach, University Students, Motivation.

\section{Introduction}

People use the media in line with their needs. Making an analysis on the needs also entails reaching findings about the ways in which the needs concerned are satisfied. The soundest way of this is to make a detailed examination on such sides of the audience as their psychological, sociopsychological, sociological, cultural, and even economic and political sides (Güngör, 2013: 122).

It is seen that today young people prefer the continually developing social media platforms to the conventional media in order to satisfy such needs of theirs as acquiring information and entertainment in particular as well as making use of leisure, self-actualization, communicating with their friends, socialization, economic utility, playing games, making comments, making a travel plan, product tracking, and sharing photographs, videos, and experiences (Pempek et al., 2009; Erol and Hassan, 2014; Hazar, 2011). In general, microsites, social networks, media sharing sites, mobile applications, games, etc. are used as social media platforms; however, preferences also vary according to the demographic characteristics of users.

When the domestic and foreign literature on what needs especially the young satisfy by using social media tools worldwide and in Turkey is examined, it is seen that there are studies which were carried out regarding various types of the social media with the approach of the theory of uses and gratifications. In the studies by Bonds and Raacke (2010), Vural and Bat (2010), Koçak (2012), Alikılıç, Gülay and Binbir (2013), Kara (2016), Aydın and Çelik (2017), and Özer (2017) out of these studies, the reasons why users preferred social media platforms and the gratifications they obtained were examined specifically concerning different social media platforms. In the studies, it is stressed that various motivations such as acquiring information, social interaction, entertainment, personal identity, guidance, and surveillance motivate people for social media use and that gratification is obtained accordingly (Koçak, 2012: 117). The reasons why individuals use the social media, their social media 
use habits and preferences, what needs of theirs they satisfy when using them and the gratifications they obtain may vary by person. Some studies performed show that the social media facilitate such actions as users' simultaneous sharing of their emotions, thoughts, and ideas with other users, their being informed by unlimited sources in different media, their acquiring of opportunities for free education everywhere, their socialization and self-expression, their finding of a medium for existence, and their relieving of their boredom. Besides these uses of the social media, it has turned out that they are preferred by many users also with their feature of allowing users to share their personal information, photographs, and videos on digital platforms (Aydın and Çelik, 2017).

These studies focus on the reasons for, and consequences of, the social media preferences of the young people who were born largely after 1990, who are either university students or university graduates, and who widely use the Internet and the social media. Considering this point, this study intends to evaluate the use motivations of the university students selected with the method of random sampling regarding YouTube, which has begun to be the most popular social media application among the social media platforms particularly in Turkey recently, and the gratifications they obtain from it through quantitative research.

While the rapidly developing digital technology is continually equipping the new media with new opportunities, the processes of content production and consumption are also turning from their forms in the conventional media into completely different forms (Karadağ, 2017: 88). Particularly upon the development of the possibilities for image recording, storage, uploading, and sharing, video communication has become an indispensable method of communication of our time and video sharing sites have begun to receive great attention throughout the whole world. YouTube is one of the most important examples of the content sharing sites that allow creating, storing, and sharing multimedia contents and works on the basis of video sharing. In this sense, the founders of YouTube define themselves as a distribution platform which was established on the global scale in order to make a connection between the original contents created and people, to give information, and to inspire others (Bonander and Marsh, 2015: 451). Established in 2005, YouTube - 15 months after its materialization - provided a new way of watching TV whereby around 100 million videos were shared per day; whereby the most popular videos were displayed by millions of users; which formed around the calendars of users; and which was not confined to fixed hours. The audience thus became an integral part of the media distribution chain (Haridakis and Hanson, 2009: 317).

Whilst the slogan of the site was initially "Your Digital Video Repository", its slogan was changed into "Broadcast Yourself" as of the period when the site won popularity (Burgess and Green, 2010: 4). In this line, it is also possible to state that YouTube, initially considered an archive tool in addition to the social media, is evaluated as a tool which provides new ways to analyze videos with its network or video sharing service (Thorson et al., 2013: 441).

YouTube, which has reached almost one-third of all Internet users through its contents that are offered for use in a total of 76 different languages in more than 90 countries today, has about 1.5 billion active users (Youtube, 2018a). 80\% of the traffic on YouTube, to which videos of about 100 hours were uploaded per minute in the early years, comes from outside the USA (Hussain, 2015: 1740). According to the data by YouTube (2018b), videos of over 400 hours per minute are uploaded to the platform today. In the research on the most popular social media sites of the world by eBizMBA.com (2018), Facebook was determined as the first with 1,500,000,000 users, YouTube as the second with 1,499,000,000 users, Twitter as the third with 400,000,000 users, and Instagram as the fourth with $275,000,000$ users. It is stated that of the users of YouTube, the second social media platform with the largest number of users worldwide, about half are university students, about $20 \%$ are university graduates, $10 \%$ are high school students, and about $10 \%$ are graduates of graduate education (Ignite SocialMedia, 2011).

In the report by Ignite Social Media (2017), in which the changes in the social media are addressed, it is stated that whilst YouTube had similar rates of use as $46 \%$ in $2013,39 \%$ in $2014,48 \%$ in 2015 , and $49 \%$ in 2016 , YouTube reached $71 \%$ rate of use in 2017 . YouTube, whose use is rapidly increasing in Turkey - as in the world - with every passing day, has been ranking first with some 27,080,969 real users among the most visited social media platforms since July 2017 (IAB Turkey, 2017). YouTube is followed by Facebook and Twitter, respectively. In Turkey, the ratings and number of users of YouTube have increased depending on the change in mobile use habits and the flourishing 
of smartphones. This increase was also determined with the research performed in 2017 by We Are Social. According to the results of the research, it was discovered that of the Internet users in Turkey, $55 \%$ watched videos every day and $24 \%$ watched videos every week (Kemp, 2017).

\section{The Theory of Uses and Gratifications}

In the first half of the 20th century, first of all, the users were placed in a user subject position with audience analyses and then tool-centered research was replaced by audience-centered research (Aydın and Çelik, 2017: 84). Observed to have first begun to be used in communication studies in the early 1960s, the theory of uses and gratifications helps one understand social networks from an analytical perspective. By thinking that the audience are active in communication, one focuses on what people do by means of the media rather than on the effect of the media on people in this theory (Katz et al., 1974).

Klapper's famous question, which brought the audience to the forefront, in 1963 provided the commencement of a new era in communication research. Not the approach "what the media do to the audience" but the approach "what the audience do with the media" now changed the perspective on the relationship between the media and the audience, thereby providing the acknowledgement of the fact that audience were more active. In addition, this approach also puts forth that media consumption takes place within consumers' consciousness. In other words, the audience are conscious of their needs. The theory of uses and gratifications, which evaluates the audience in the dominant position in the communication process, is an approach which changes the effect paradigm that dominates the process of mass communication. Focusing on the question of what the people do with the means of mass media, this approach states that the receiver, i.e. the audience, is active in mass communication (Erdoğan and Alemdar, 2002: 187-188). Individuals incline to the media purposefully and in order to satisfy various needs of theirs and they select and consume the contents according to these needs of theirs (YIImaz, 2016: 397).

With the studies carried out in this line and with the uses and gratifications approach, it was clarified that people reached some gratifications by using the media. Such researchers as Lazarsfeld, Katz, and Klapper presented the first systematic perspective on the model. Referred to as K\&D, the model focused on two fundamental developments. The first one was the participation of individuals in media production, while the second one was individuals' use of the means of mass media as human needs (Cited from Lull, 2001: 129 by Ayhan and Çavuş, 2014: 37). Later on, the most important contribution to the field was made by the study entitled 'Uses and Gratifications Research' and written by Katz, Blumler, and Gurevitch. According to the theory developed by Katz, Blumler, and Gurevitch, there are four types of needs that can enable one to reach gratification through the use of the media, namely cognitive, affective, and social integrative needs and habit. According to the theory again, the media are the subject of entertainment and passing time as much as of information and interaction. Furthermore, selecting media contents and using them may change under the influence of psychological tendencies and social roles (Katz et al., 1974: 510).

The studies on the theory continued and Rosengren developed the model by making some additions to the model by Katz, Blumler, and Gurevitch. For instance, in the model developed by Rosengren, needs should occur as a problem in order for people to act. Therefore, Rosengren places emphasis on the biological and psychological infrastructures that form the basis for human behavior. People act and react on these two bases. The basic human needs are addressed under five headings: (1) psychological needs, (2) security needs, (3) needs for belonging and love, (4) needs for reputation, and (5) the need for self-actualization (Ayhan and Çavuş, 2014: 38).

In the study by McQuail (1987: 73), a study carried out regarding the satisfaction of needs specifically by means of media tools, the typology of the common reasons for media/television use was addressed more widely and gathered under four distinct groups.

1. Information: The need to acquire information about the events in the immediate vicinity, in the society, and worldwide. The need to seek recommendations in the practical, idea or decision-making processes. To satisfy curiosity and the general interest. To learn and the need for self-education. The need to acquire the sense of security by means of information. 
2. Personal Identity: The need to find support for personal values. The need to find behavioral models. The need to identify oneself with the reputable people in the media. The need to acquire one's own perspective.

3. Integration and Social Interaction: Social empathy. To acquire the sense of belonging by identifying with other people. To find a basis for talking and forming social interaction. Their replacing of the friendship in real life. Their helping with the fulfilment of social roles. Their helping with the relationships with the family, friends, and the society.

4. Entertainment: To escape from problems. To relax. To pass time. To take pleasure in cultural and aesthetic terms. Sentimental broadcast. Sexual arousal.

Many studies on conventional and social media platforms have been carried out within the framework of the theory of uses and gratifications. Particularly due to the widespread Internet use among the young, the Internet use motivations of university students indicate different basic factors in various studies. For instance, in the research on Internet uses and gratifications by Papacharissi and Rubin, 5 basic factors were determined in the research performed with respect to Internet gratifications on those students from Midwestern University who attended news and chat groups, who developed their personal Internet sites, and who attended a course. They were interpersonal utility, passing time, seeking information, suitability/convenience, and entertainment, respectively (Papacharissi and Rubin, 2000: 185).

In the research on the university students in Turkey carried out by Balcı and Ayhan on the basis of the K\&D model, it was intended to explain the relationship between the factors affecting the inclination of the university students towards the Internet with such variables as respondents' Internet use experience and skill, the duration of their weekly Internet use, the duration of their daily Internet use, the trust in the Internet, and some characteristics of the respondents. Some 6 factors affecting the inclination of the respondents towards the Internet were determined within the scope of the research. These factors were social escape, information, making use of leisure, economic utility, social interaction, chat, and entertainment in order of importance (Balcı and Ayhan, 2007: 193).

It is seen that the factors found effective on Internet use motivations are also effective on the motivations for the use of social media platforms. Moreover, the same effects are also encountered in the use motivations in the social media platforms with uses similar to those of the conventional media. One of the studies similar to the motivations and preferences for using YouTube is the study by Rubin and Bantz (1987). In the study concerned, the use and gratification motivations about videos and video recorders were investigated and it was established that these tools were used within the framework of the factors of library storage, video or music recording exercises, movie rental, child viewing, time shifting, and socialization. In their research on video games, Sherry et al. determined the factors of competition, challenging, social interaction, attractiveness, fantasy, and arousal (Sherry et al., 2006: 218-219). In a study Wang - a researcher who examined the motivations concerning YouTube - carried out to reveal the relationship among the motivations for using video sharing sites, online reputation management, dissemination of innovations, and video sharing site behavior in Taiwan with the method of an online survey, she concluded that the users obtained more gratifications from video sharing sites with an increase in their durations of use (Wang, 2014: 148). Khan examined the use motivations of YouTube users in the context of uses and gratifications and performed an online survey with some 1,143 registered YouTube users. In his research, Khan concluded that the strongest determinant for liking and disliking videos was the motivation of entertainment, that the strongest determinant for making comments on videos and uploading videos was the motivation of social interaction, and that the strongest determinant for sharing videos was the motivation of giving information (Khan, 2017: 236).

As a result of the studies carried out, it is observed that use motivations multiply according to needs. Whiting and Williams (2013) put forward that there are 10 motivations in the uses and gratifications approach. These motivations are social interaction, information seeking, passing time, entertainment, relaxation, communicatory utility, convenience utility, expression of opinion, information sharing, knowledge about others, and surveillance.

Besides the change in social media use motivations over years, it is seen that the factors of uses and gratifications obtained by users have also varied according to the features of the social media platforms they use. According to the results of the research Akçay (2011: 147) performed on 
the young people at Gümüşhane University in the context of the uses and gratifications approach, in which it was intended to determine the social media use frequency and motivations and to discover the gratifications obtained by users, the first factor accounting for the gratification obtained from social media use among the factors affecting social media use was the acquisition of a social environment/socialization, whereas the second factor was entertainment/passing leisure. In a study Solmaz et al. (2013: 31) carried out in the sample of the students in the Faculty of Communication at Selçuk University, such reasons as sharing photographs and information, having fun and relaxation, making use of leisure, having knowledge or accessing information, sending and receiving messages, following events or the agenda, reaching people and organizations with the contact information of people, and exchanging ideas are among the reasons of high priority among the reasons why social sharing sites are used the most. In the research by Akyıldız and Argan, which questioned with what uses and gratifications factors Facebook was used, it turned out that the users used Facebook to acquire a social environment/for socialization, for entertainment/to pass leisure, for relaxation/to escape from stress, and to acquire information/get to know life (Akyıldız and Argan, 2015: 46). On the other hand, in the study Küçükkurt et al. carried out to quantify the views of university students about the media from the perspective of the theory of uses and gratifications, they stated that of the uses and gratifications factors, "affective needs" (to form new friendships) constituted the most important factor, thereby indicating a point which differed from the above-mentioned research results (Küçükkurt et al., 2009: 48). In the research on the students in the Faculty of Communication at Gümüşhane University by Çalışır (2015: 126-127), again a similar study, it is seen that $28 \%$ of the students used social networks to reach information. The factors "to have fun", "to read news" and "to pass time" were also preferred in the top ranks by the students and the findings also included students' use of the social media in order to find out what their friends did, although at a very small rate.

\section{Research}

It is seen that young people today prefer the continually developing social media platforms to the conventional media in order to satisfy such needs of theirs as acquiring information and entertainment in particular as well as making use of leisure, self-actualization, communicating with their friends, socialization, economic utility, playing games, making comments, making a travel plan, product tracking, and sharing photographs, videos, and experiences. The use motivations among university students for YouTube, largely preferred by the young people who shared contents via videos, and the gratifications they obtained were determined in this study.

The study aimed to reveal by means of what tool and with what use motivation the university students used YouTube weekly and daily the most in the context of the uses and gratifications approach. A literature review was carried out regarding the elements which influenced users' YouTube use motivations and 54 items were determined. In this context, a survey of a total of 81 questions - 54 field and 27 demographic - was performed in December 2017 by employing the method of random sampling so as to reveal the use motivations of some 579 university students.

Research question: "By means of what tool and with what use motivation the university students use YouTube weekly and daily the most according to the uses and gratifications approach and how do the use motivations interact with each other?"

Within this scope, the research hypotheses are as follows:

Hypothesis 1: In the context of the uses and gratifications approach, the university students use YouTube to acquire information and follow news the most.

Hypothesis 2: The university students use YouTube for an hour to 3 hours per day.

Hypothesis 3: The university students use YouTube on each day of the week.

Hypothesis 4: In the context of the uses and gratifications approach, there is an interaction among the use motivations of the university students.

Hypothesis 5: In the context of the uses and gratifications approach, the university students prefer mobile devices for daily and weekly YouTube use.

Hypothesis 6: There is a linear relationship between the large number of channels followed on YouTube and YouTube use motivations. 
Hypothesis 7: There is a linear relationship between the use in order to increase the number of available followers on YouTube and the use for social interaction and to acquire reputation/become famous.

Hypothesis 8: Users' possessing of a YouTube account affects their YouTube use motivations.

Hypothesis 9: Users' use of their real name in their YouTube account affects their YouTube use motivations.

The outstanding items in the studies within the scope of the literature regarding what the YouTube use motivations of university students were in the context of the uses and gratifications approach were addressed in the survey questions. As a result of the reliability test done, it was observed that Cronbach's alpha value turned out to be 0.963 . The alpha value obtained shows that the study is adequately reliable. A factor analysis was made on the available items and the following ten factors were determined. The KMO and Bartlett's ToS values obtained verify that the questions were appropriate for the factor analysis $(\mathrm{KMO}=0.936$; Bartlett's Test of Sphericity $p=0.000)$.

When Table 1 is considered, it is seen that in the context of the uses and gratifications approach, the university students used YouTube to acquire information and reach alternative information, to access alternative news broadcasting, to obtain economic and social utility, for social interaction, for self-actualization, for education, for self-expression, for entertainment, to acquire reputation and become famous, and to reach customer experience, respectively.

\begin{tabular}{lrrr}
\hline & Total & $\begin{array}{r}\text { Percentage } \\
\text { of Variance }\end{array}$ & $\begin{array}{r}\text { Cumulative } \\
\text { Percentage }\end{array}$ \\
\hline $\begin{array}{l}\text { F1. The factor "Using YouTube to acquire information and reach } \\
\quad \text { llternative information" }\end{array}$ & 18.559 & 34.369 & 34.369 \\
\hline $\begin{array}{l}\text { F2. The factor "Using YouTube to access alternative news } \\
\text { broadcasting" }\end{array}$ & 6.279 & 11.628 & 45.997 \\
\hline F3. The factor "Using YouTube to obtain economic and social utility" & 2.861 & 5.299 & 51.296 \\
\hline F4. The factor "Using YouTube for social interaction" & 1.826 & 3.382 & 54.677 \\
\hline F5. The factor "Using YouTube for self-actualization" & 1.540 & 2.851 & 57.529 \\
\hline F6. The factor "Using YouTube for education" & 1.418 & 2.625 & 60.154 \\
\hline F7. The factor "Using YouTube for self-expression" & 1.291 & 2.390 & 62.544 \\
\hline F8. The factor "Using YouTube for entertainment" & 1.180 & 2.186 & 64.730 \\
\hline $\begin{array}{l}\text { F9. The factor "Using YouTube to acquire reputation and become } \\
\text { famous" }\end{array}$ & 1.086 & 2.012 & 66.742 \\
\hline F10. The factor "Using YouTube to reach customer experience" & 1.062 & 1.967 & 68.709 \\
\hline
\end{tabular}

Table 1. Extraction Sums of Squared Loadings

According to the above-mentioned findings, the hypothesis "In the context of the uses and gratifications approach, the university students use YouTube to acquire information and follow news the most" (Hypothesis 1) was accepted.

The following were determined in the descriptive analysis of the responses provided:

All respondents $(100 \%$ of them) were active university students. The ages of the active university students included in the scope of the research were in the age range of 18-56 years. Accordingly, $14.5 \%$ of them were 19 years old; $23.1 \%$ of them were 20 years old; $20.6 \%$ of them were 21 years old; $15.0 \%$ of them were 22 years old; $9.8 \%$ of them were 23 years old; and the remaining percentage consisted of the other age groups. Of the respondents, $7.6 \%$ had YouTube use experience for less than a year, $16.5 \%$ for a year to 3 years, $35.3 \%$ for 4 to 6 years, $25.3 \%$ for 7 to 9 years, and $15.3 \%$ for 10 years and more. Of the respondents, $54.9 \%$ were female and $45.1 \%$ were male. $84.1 \%$ of the respondents were foundation university students, whereas $15.9 \%$ of them were state university students.

The rate of those who said that they had used YouTube in the last two months was $99.1 \%$, while the rate of those who said that they had not done so was $0.9 \%$. The rate of those who said that they had a YouTube account was $64.1 \%$, whereas the rate of those who said that they had no account was $35.9 \%$. Of the respondents, $74.9 \%$ stated that they used their real name in their YouTube user account and $25.1 \%$ stated that they did not use their real name in their YouTube user account. Of the 
respondents, $1.6 \%$ stated that they did not follow any channels on YouTube, $32.4 \%$ stated that they followed a channel to 9 channels on YouTube, 42.9\% stated that they followed 10 to 29 channels on YouTube, $11.3 \%$ stated that they followed 30 to 59 channels on YouTube, and $11.8 \%$ stated that they followed 60 channels and more on YouTube. Of the respondents, $22.9 \%$ stated that the number of their followers was zero (0), 30.5\% stated that they had a follower to 9 followers, $28.0 \%$ stated that they had 10 to 28 followers, $5.1 \%$ stated that they had 30 to 57 followers, and $13.6 \%$ stated that they had 60 followers and more.

Of the respondents, $33.8 \%$ stated that they used YouTube by means of a mobile device for less than an hour per day, $39.9 \%$ for an hour to 3 hours per day, $12.5 \%$ for 3 to 5 hours per day, and $9.9 \%$ for more than 5 hours per day. $3.8 \%$ of the respondents stated that they never used YouTube by means of a mobile device daily. Of the respondents, $73.7 \%$ stated that they never used YouTube by means of a tablet, while $13.8 \%$ stated that they used YouTube by means of a tablet for less than an hour per day, $6.4 \%$ for an hour to 3 hours per day, $3.8 \%$ for 3 to 5 hours per day, and $2.3 \%$ for more than 5 hours per day. $29.2 \%$ of the respondents stated that they never used YouTube by means of a laptop, whereas $30.5 \%$ of them stated that they used YouTube by means of a laptop for less than an hour per day, $24.6 \%$ of them for an hour to 3 hours per day, $11.4 \%$ of them for 3 to 5 hours per day, and $4.2 \%$ of them for more than 5 hours per day. Of the respondents, $68.2 \%$ stated that they never used YouTube by means of a desktop, while 14.1\% stated that they used YouTube by means of a desktop for less than an hour per day, $10.3 \%$ for an hour to 3 hours per day, $3.6 \%$ for 3 to 5 hours per day, and $3.8 \%$ for more than 5 hours per day. Of the respondents, $50.1 \%$ stated that they never used YouTube by means of the smart televisions which could connect to the Internet, whereas $21.7 \%$ stated that they used YouTube by means of the smart televisions which could connect to the Internet for less than an hour per day, $16.8 \%$ for an hour to 3 hours per day, $6.6 \%$ for 3 to 5 hours per day, and $4.9 \%$ for more than 5 hours per day.

According to the above-mentioned findings, the hypothesis "The university students use YouTube for an hour to $\mathbf{3}$ hours daily." (Hypothesis 2) was accepted.

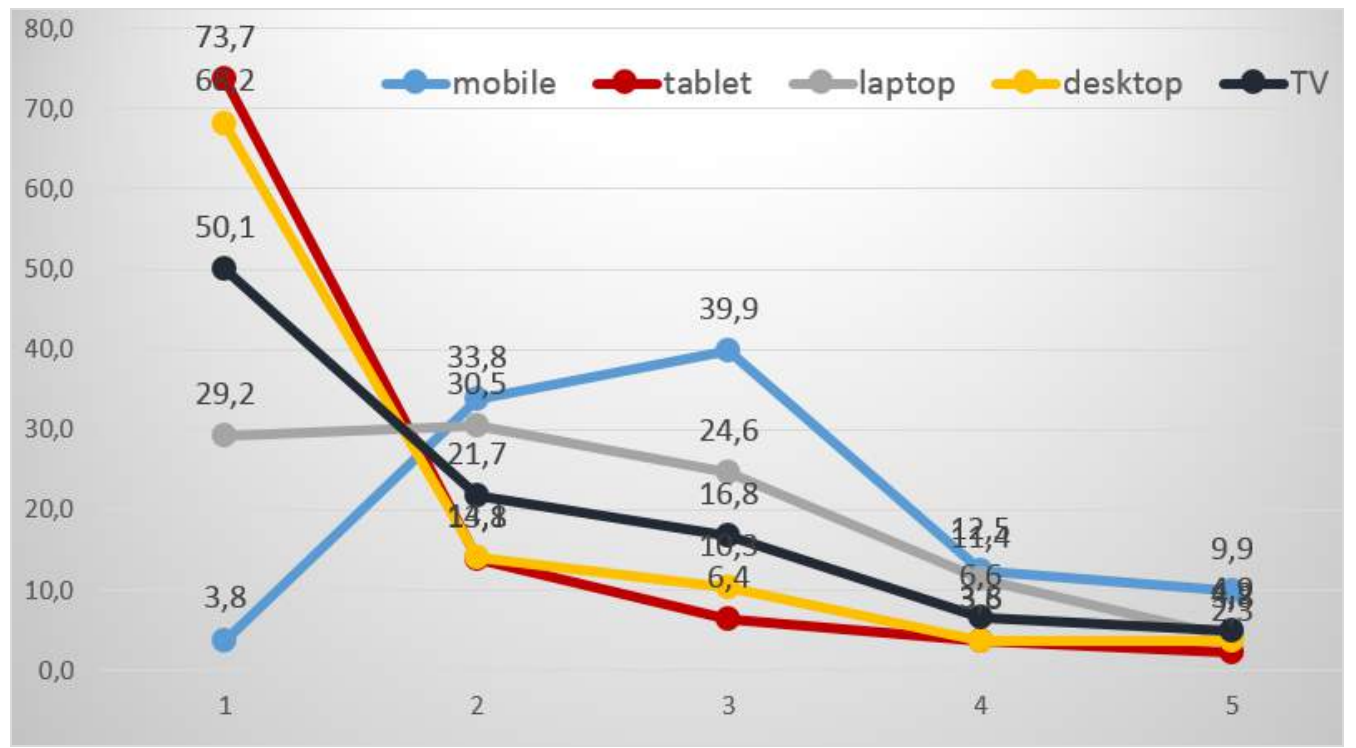

Graph 1. Respondents' Durations of Daily YouTube Use. 


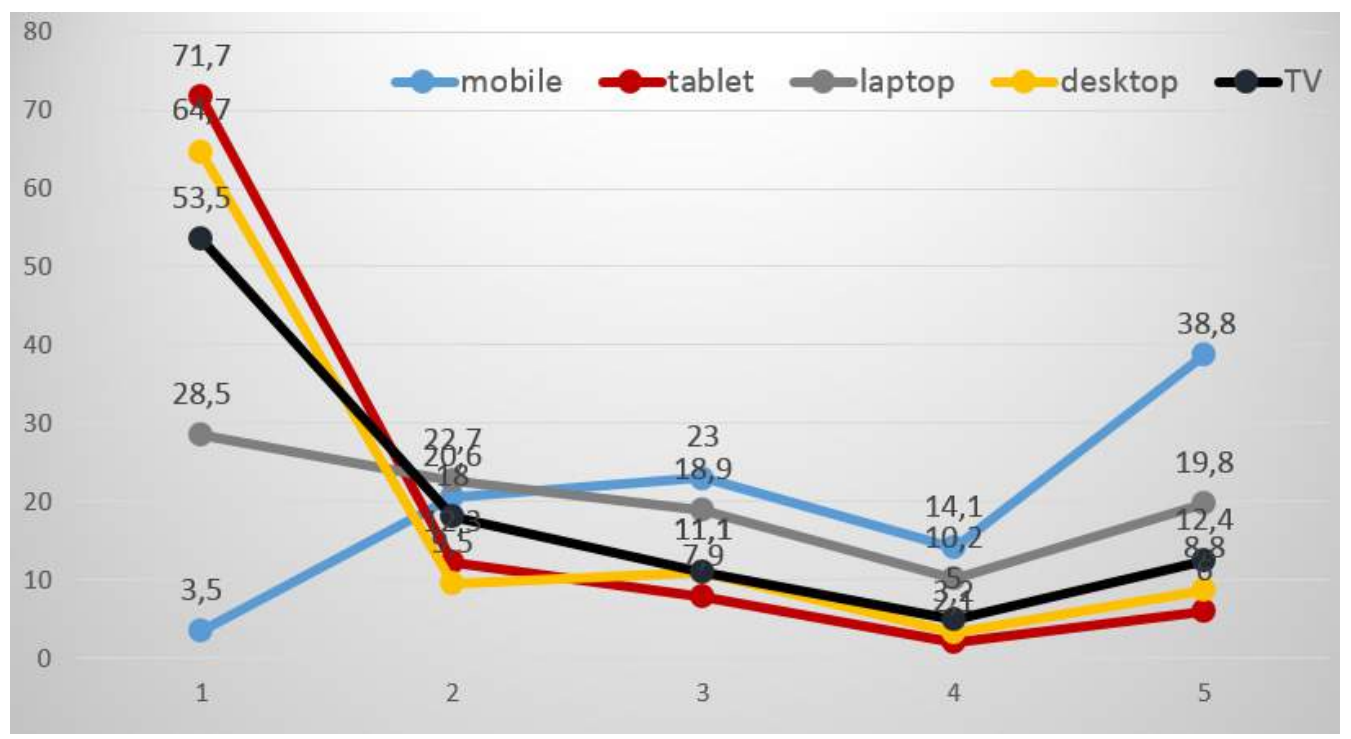

Graph 2. Respondents' Weekly YouTube Use Frequencies.

Of the respondents, $20.6 \%$ stated that they used YouTube by means of a mobile device for a day to 2 days per week, $23.0 \%$ for 3 to 4 days per week, $14.1 \%$ for 5 to 6 days per week, and $38.8 \%$ on each day of the week. 3.5\% of the respondents stated that they never used YouTube by means of a mobile device weekly. $71.7 \%$ of the respondents stated that they never used YouTube by means of a tablet weekly. Of the respondents, $12.3 \%$ stated that they used YouTube by means of a tablet for a day to 2 days per week, $7.9 \%$ for 3 to 4 days per week, $2.1 \%$ for 5 to 6 days per week, and $6.0 \%$ on each day of the week. $28.5 \%$ of the respondents never used YouTube by means of a laptop weekly. Of the respondents, $22.7 \%$ stated that they used YouTube by means of a laptop for a day to 2 days per week, $18.9 \%$ for 3 to 4 days per week, $10.2 \%$ for 5 to 6 days per week, and $19.8 \%$ on each day of the week. $64.7 \%$ of the respondents stated that they never used YouTube by means of a desktop weekly. Of the respondents, $9.5 \%$ stated that they used YouTube by means of a desktop for a day to 2 days per week, $11.1 \%$ for 3 to 4 days per week, 3.2\% for 5 to 6 days per week, and $8.8 \%$ on each day of the week. 53.5\% of the respondents stated that they never used YouTube weekly by means of the smart televisions which could connect to the Internet. Of the respondents, $18.0 \%$ stated that they used YouTube by means of the smart televisions which could connect to the Internet for a day to 2 days per week, $11.1 \%$ for 3 to 4 days per week, $5.0 \%$ for 5 to 6 days per week, and $12.4 \%$ on each day of the week.

According to the above-mentioned findings, the hypothesis "The university students use YouTube on each day of the week." (Hypothesis 3 ) was accepted.

Inferential analyses were made on the basis of the factors determined. These analyses are Correlation analyses, Mann-Whitney and Kruskal-Wallis tests, and median calculations.

There is a positive correlation between the factors "Using YouTube to acquire information and reach alternative information" (F1) and "Using YouTube to access alternative news broadcasting" (F2) $(r h o=0.565 ; p=0.000)$. There is a positive correlation between the factors "Using YouTube to acquire information and reach alternative information" (F1) and "Using YouTube for social interaction" (F4) $(r h o=0.234 ; p=0.000)$. There is a positive correlation between the factors "Using YouTube to acquire information and reach alternative information" (F1) and "Using YouTube for education" (F6) $(r h o=0.475 ; p=0.000)$. There is a positive correlation between the factors "Using YouTube to acquire information and reach alternative information" (F1) and "Using YouTube for self-expression" (F7) $(r h o=0.272 ; p=0.000)$. There is a positive correlation between the factors "Using YouTube to acquire information and reach alternative information" $(F 1)$ and "Using YouTube for entertainment" (F8) $(r h o=0.633 ; p=0.000)$. There is a positive correlation between the factors "Using YouTube to acquire information and reach alternative information" $(\mathrm{F} 1)$ and "Using YouTube to acquire reputation and become famous" (F9) ( $r h o=0.191 ; p=0.000$ ). There is a positive correlation between the factors "Using YouTube to acquire information and reach alternative information" (F1) and "Using YouTube to reach customer experience" $(\mathrm{F} 10)(\mathrm{rho}=0.564 ; \mathrm{p}=0.000)$. There is a positive correlation between the factors 
"Using YouTube to access alternative news broadcasting" (F2) and "Using YouTube for social interaction" (F4) (rho=0.242; $\mathrm{p}=0.000)$. There is a positive correlation between the factors "Using YouTube to access alternative news broadcasting" (F2) and "Using YouTube for self-actualization" (F5) (rho=0.089; $\mathrm{p}=0.033$ ). There is a positive correlation between the factors "Using YouTube to access alternative news broadcasting" (F2) and "Using YouTube for education" (F6) (rho=0.494; $\mathrm{p}=0.000$ ). There is a positive correlation between the factors "Using YouTube to access alternative news broadcasting" (F2) and "Using YouTube for self-expression" (F7) (rho=0.380; $p=0.000$ ). There is a positive correlation between the factors "Using YouTube to access alternative news broadcasting" (F2) and "Using YouTube for entertainment" ( $F 8)$ ( $r h o=0.566 ; p=0.000)$. There is a positive correlation between the factors "Using YouTube to access alternative news broadcasting" (F2) and "Using YouTube to acquire reputation and become famous" ( $F 9)$ (rho=0.260; $p=0.000$ ). There is a positive correlation between the factors "Using YouTube to access alternative news broadcasting" (F2) and "Using YouTube to reach customer experience" ( $F 10)$ ( $r h o=0.429 ; p=0.000)$. There is a positive correlation between the factors "Using YouTube to obtain economic and social utility" (F3) and "Using YouTube for social interaction" (F4) ( $r h o=0.341 ; p=0.000$ ). There is a positive correlation between the factors "Using YouTube to obtain economic and social utility" (F3) and "Using YouTube for selfactualization" (F5) (rho=0.542; $\mathrm{p}=0.000$ ). There is a positive correlation between the factors "Using YouTube to obtain economic and social utility" (F3) and "Using YouTube for education" (F6) $(\mathrm{rho}=0.331 ; \mathrm{p}=0.000)$. There is a positive correlation between the factors "Using YouTube to obtain economic and social utility" (F3) and "Using YouTube for self-expression" (F7) (rho=0.426; $p=0.000$ ). There is a positive correlation between the factors "Using YouTube to obtain economic and social utility" (F3) and "Using YouTube for entertainment" (F8) (rho=0.114; $\mathrm{p}=0.006)$. There is a positive correlation between the factors "Using YouTube to obtain economic and social utility" (F3) and "Using YouTube to acquire reputation and become famous" ( $F 9)$ ( $r h o=0.562 ; p=0.000)$. There is a positive correlation between the factors "Using YouTube to obtain economic and social utility" (F3) and "Using YouTube to reach customer experience" $(F 10)(r h o=0.180 ; p=0.000)$. There is a positive correlation between the factors "Using YouTube for social interaction" (F4) and "Using YouTube for selfactualization" (F5) ( $r h o=0.290 ; p=0.000)$. There is a positive correlation between the factors "Using YouTube for social interaction" (F4) and "Using YouTube for education" ( $F 6)$ (rho=0.269; $p=0.000$ ). There is a positive correlation between the factors "Using YouTube for social interaction" (F4) and "Using YouTube for self-expression" ( $F 7)(\mathrm{rho}=0.534 ; \mathrm{p}=0.000)$. There is a positive correlation between the factors "Using YouTube for social interaction" (F4) and "Using YouTube for entertainment" (F8) (rho=0.282; $\mathrm{p}=0.000)$. There is a positive correlation between the factors "Using YouTube for social interaction" (F4) and "Using YouTube to acquire reputation and become famous" (F9) (rho=0.377; $\mathrm{p}=0.000$ ). There is a positive correlation between the factors "Using YouTube for social interaction" (F4) and "Using YouTube to reach customer experience" (F10) (rho=0.194; $\mathrm{p}=0.000$ ). There is a positive correlation between the factors "Using YouTube for self-actualization" (F5) and "Using YouTube for education" (F6) (rho=0.277; $\mathrm{p}=0.000)$. There is a positive correlation between the factors "Using YouTube for self-actualization" (F5) and "Using YouTube for selfexpression" (F7) (rho=0.545; $\mathrm{p}=0.000$ ). There is a positive correlation between the factors "Using YouTube for self-actualization" (F5) and "Using YouTube to acquire reputation and become famous" ( $F 9)(r h o=0.593 ; p=0.000)$. There is a positive correlation between the factors "Using YouTube for selfactualization" (F5) and "Using YouTube to reach customer experience" ( $F 10)$ (rho=0.102; $p=0.015$ ). There is a positive correlation between the factors "Using YouTube for education" (F6) and "Using YouTube for self-expression" (F7) ( $r h o=0.415 ; p=0.000)$. There is a positive correlation between the factors "Using YouTube for education" (F6) and "Using YouTube for entertainment" (F8) (rho=0.498; $\mathrm{p}=0.000$ ). There is a positive correlation between the factors "Using YouTube for education" (F6) and "Using YouTube to acquire reputation and become famous" ( $F 9)$ (rho=0.446; $p=0.000$ ). There is a positive correlation between the factors "Using YouTube for education" (F6) and "Using YouTube to reach customer experience" ( $F 10)(r h o=0.468 ; p=0.000)$. There is a positive correlation between the factors "Using YouTube for self-expression" (F7) and "Using YouTube for entertainment" (F8) $(r h o=0.332 ; p=0.000)$. There is a positive correlation between the factors "Using YouTube for selfexpression" (F7) and "Using YouTube to acquire reputation and become famous" (F9) (rho=0.568; $p=0.000$ ). There is a positive correlation between the factors "Using YouTube for self-expression" (F7) and "Using YouTube to reach customer experience" ( $F 10)(r h o=0.251 ; p=0.000)$. There is a positive correlation between the factors "Using YouTube for entertainment" (F8) and "Using YouTube to acquire reputation and become famous" ( $F 9)$ ( $r h o=0.244 ; p=0.000$ ). There is a positive correlation between the factors "Using YouTube for entertainment" (F8) and "Using YouTube to reach customer experience" ( $F 10)(r h o=0.467 ; p=0.000)$. There is a positive correlation between the factors "Using 
YouTube to acquire reputation and become famous" (F9) and "Using YouTube to reach customer experience" (F10) (rho=0.229; $p=0.000)$ (See Table 2).

\begin{tabular}{|c|c|c|c|c|c|c|c|c|c|c|}
\hline & F1 & F2 & F3 & F4 & F5 & F6 & F7 & F8 & F9 & F10 \\
\hline F1 $\uparrow$ & & $\uparrow$ & & $\uparrow$ & & $\uparrow$ & $\uparrow$ & $\uparrow$ & $\uparrow$ & $\uparrow$ \\
\hline F2 $\uparrow$ & & & & $\uparrow$ & $\uparrow$ & $\uparrow$ & $\uparrow$ & $\uparrow$ & $\uparrow$ & $\uparrow$ \\
\hline F3 $\uparrow$ & & & & $\uparrow$ & $\uparrow$ & $\uparrow$ & $\uparrow$ & $\uparrow$ & $\uparrow$ & $\uparrow$ \\
\hline F4 $\uparrow$ & & & & & $\uparrow$ & $\uparrow$ & $\uparrow$ & $\uparrow$ & $\uparrow$ & $\uparrow$ \\
\hline F5 $\uparrow$ & & & & & & $\uparrow$ & $\uparrow$ & & $\uparrow$ & $\uparrow$ \\
\hline F6 $\uparrow$ & & & & & & $\uparrow$ & $\uparrow$ & $\uparrow$ & $\uparrow$ \\
\hline F7 $\uparrow$ & & & & & & & & $\uparrow$ & $\uparrow$ & $\uparrow$ \\
\hline F8 $\uparrow$ & & & & & & & & & $\uparrow$ & $\uparrow$ \\
\hline F9 $\uparrow$ & & & & & & & & & & $\uparrow$ \\
\hline
\end{tabular}

Table 2. The Ball of Positive Correlations among the Research Factors.

In Table 2, it is seen that of the university students, those who used motivations F1, F2, and F3 out of the YouTube use motivations had a linear relationship with seven of ten motivations. Briefly, it is seen that the respondents who used YouTube to acquire information and reach alternative information (F1), to access alternative news broadcasting (F2), and to obtain economic and social utility (F3) had the other motivations too.

According to the above-mentioned findings, the hypothesis "In the context of the uses and gratifications approach, there is an interaction among the use motivations of the university students." (Hypothesis 4) was accepted.

There is a positive correlation between the duration of daily YouTube use by means of a mobile device and the factor "Using YouTube to access alternative news broadcasting" (F2) $(r h o=0.124 ; p=0.003)$. There is a positive correlation between the duration of daily YouTube use by means of a mobile device and the factor "Using YouTube to obtain economic and social utility" (F3) $(r h o=0.189 ; p=0.000)$. There is a positive correlation between the duration of daily YouTube use by means of a mobile device and the factor "Using YouTube for social interaction" (F4) (rho=0.113; $\mathrm{p}=0.007$ ). There is a positive correlation between the duration of daily YouTube use by means of a mobile device and the factor "Using YouTube for self-actualization" (F5) ( $r h o=0.162 ; p=0.000)$. There is a positive correlation between the duration of daily YouTube use by means of a mobile device and the factor "Using YouTube for education" $(F 6)(r h o=0.128 ; p=0.002)$. There is a positive correlation between the duration of daily YouTube use by means of a mobile device and the factor "Using YouTube for self-expression" ( $F 7$ ) ( $r h o=0.197 ; p=0.000$ ). There is a positive correlation between the duration of daily YouTube use by means of a mobile device and the factor "Using YouTube for entertainment" ( $F 8$ ) ( $r h o=0.093 ; p=0.025)$. There is a positive correlation between the duration of daily YouTube use by means of a mobile device and the factor "Using YouTube to acquire reputation and become famous" ( $F 9)$ ( $r h o=0.172 ; p=0.000$ ). There is a positive correlation between the duration of daily YouTube use by means of a mobile device and the factor "Using YouTube to reach customer experience" $(\mathrm{F} 10)(\mathrm{rho}=0.083 ; \mathrm{p}=0.047)$.

There is a positive correlation between the duration of daily YouTube use by means of a tablet and the factor "Using YouTube to obtain economic and social utility" (F3) (rho=0.152; $p=0.000)$. There is a positive correlation between the duration of daily YouTube use by means of a tablet and the factor "Using YouTube for self-actualization" (F5) ( $r h o=0.146 ; p=0.001)$. There is a positive correlation between the duration of daily YouTube use by means of a tablet and the factor "Using YouTube for self-expression" (F7) (rho=0.102; $p=0.019$ ). There is a positive correlation between the duration of daily YouTube use by means of a tablet and the factor "Using YouTube to acquire reputation and become famous" (F9) (rho=0.142; $\mathrm{p}=0.001)$. 
There is a positive correlation between the duration of daily YouTube use by means of a laptop and the factor "Using YouTube to acquire information and reach alternative information" (F1) ( $r h o=0.139 ; p=0.001$ ). There is a positive correlation between the duration of daily YouTube use by means of a laptop and the factor "Using YouTube to access alternative news broadcasting" (F2) ( $r h o=0.175 ; p=0.000)$. There is a positive correlation between the duration of daily YouTube use by means of a laptop and the factor "Using YouTube to obtain economic and social utility" (F3) (rho=0.135; $p=0.002$ ). There is a positive correlation between the duration of daily YouTube use by means of a laptop and the factor "Using YouTube for social interaction" (F4) (rho=0.135; $p=0.002$ ). There is a positive correlation between the duration of daily YouTube use by means of a laptop and the factor "Using YouTube for self-actualization" (F5) (rho=0.142; $p=0.001)$. There is a positive correlation between the duration of daily YouTube use by means of a laptop and the factor "Using YouTube for education" (F6) (rho=0.113; $p=0.009)$. There is a positive correlation between the duration of daily YouTube use by means of a laptop and the factor "Using YouTube for selfexpression" (F7) ( $r h o=0.174 ; p=0.000)$. There is a positive correlation between the duration of daily YouTube use by means of a laptop and the factor "Using YouTube for entertainment" (F8) (rho=0.144; $p=0.001)$. There is a positive correlation between the duration of daily YouTube use by means of a laptop and the factor "Using YouTube to acquire reputation and become famous" (F9) (rho=0.137; $p=0.001)$. There is a positive correlation between the duration of daily YouTube use by means of a laptop and the factor "Using YouTube to reach customer experience" (F10) (rho=0.141; $p=0.001)$.

There is a negative correlation between the duration of daily YouTube use by means of a desktop and the factor "Using YouTube to acquire information and reach alternative information" (F1) ( $r$ ho=-0.109; $p=0.013$ ). There is a positive correlation between the duration of daily YouTube use by means of a desktop and the factor "Using YouTube to obtain economic and social utility" (F3) ( $r$ ho $=0.173 ; p=0.000)$. There is a positive correlation between the duration of daily YouTube use by means of a desktop and the factor "Using YouTube for social interaction" (F4) (rho=0.111; $p=0.011)$. There is a positive correlation between the duration of daily YouTube use by means of a desktop and the factor "Using YouTube for self-actualization" (F5) (rho=0.212; $p=0.000$ ). There is a positive correlation between the duration of daily YouTube use by means of a desktop and the factor "Using YouTube for self-expression" (F7) ( $r h o=0.114 ; p=0.009)$. There is a positive correlation between the duration of daily YouTube use by means of a desktop and the factor "Using YouTube to acquire reputation and become famous" (F9) (rho=0.134; $\mathrm{p}=0.002$ ).

There is a positive correlation between the duration of daily YouTube use by means of a smart TV and the factor "Using YouTube to obtain economic and social utility" (F3) (rho=0.207; $p=0.000$ ). There is a positive correlation between the duration of daily YouTube use by means of a smart TV and the factor "Using YouTube for self-actualization" (F5) (rho=0.129; $p=0.003$ ). There is a positive correlation between the duration of daily YouTube use by means of a smart TV and the factor "Using YouTube for education" (F6) (rho=0.146; $p=0.001$ ). There is a positive correlation between the duration of daily YouTube use by means of a smart TV and the factor "Using YouTube for selfexpression" (F7) ( $r h o=0.128 ; p=0.003$ ). There is a positive correlation between the duration of daily YouTube use by means of a smart TV and the factor "Using YouTube to acquire reputation and become famous" (F9) (rho=0.198; $p=0.000$ ) (See Table 3).

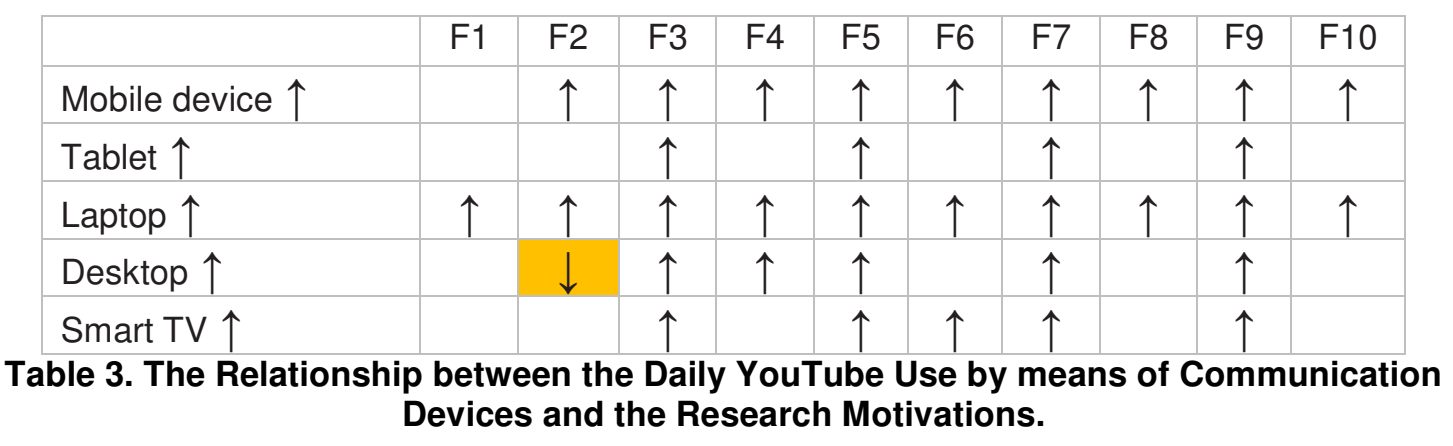

When the relationship between the communication devices and the daily YouTube use motivations is considered, it is seen that there is a significant relationship between a laptop and the 
YouTube use motivations the most. There is a significant relationship with a laptop in each of the ten motivations.

There is a positive correlation between the frequency of weekly YouTube use by means of a mobile device and the factor "Using YouTube to acquire information and reach alternative information" ( $F 1)(r h o=0.161 ; p=0.000)$. There is a positive correlation between the frequency of weekly YouTube use by means of a mobile device and the factor "Using YouTube to access alternative news broadcasting" (F2) (rho=0.174; $\mathrm{p}=0.000$ ). There is a positive correlation between the frequency of weekly YouTube use by means of a mobile device and the factor "Using YouTube for social interaction" ( $F 4$ ) (rho=0.084; $\mathrm{p}=0.046$ ). There is a positive correlation between the frequency of weekly YouTube use by means of a mobile device and the factor "Using YouTube for education" (F6) (rho $=0.141 ; p=0.001)$. There is a positive correlation between the frequency of weekly YouTube use by means of a mobile device and the factor "Using YouTube for self-expression" (F7) (rho=0.156; $p=0.000$ ). There is a positive correlation between the frequency of weekly YouTube use by means of a mobile device and the factor "Using YouTube for entertainment" (F8) (rho=0.234; $p=0.000)$. There is a positive correlation between the frequency of weekly YouTube use by means of a mobile device and the factor "Using YouTube to acquire reputation and become famous" (F9) (rho=0.086; $p=0.041$ ). There is a positive correlation between the frequency of weekly YouTube use by means of a mobile device and the factor "Using YouTube to reach customer experience" ( $F 10)$ (rho=0.128; $p=0.002$ ).

There is a positive correlation between the frequency of weekly YouTube use by means of a tablet and the factor "Using YouTube to obtain economic and social utility" (F3) (rho=0.177; $p=0.000$ ). There is a positive correlation between the frequency of weekly YouTube use by means of a tablet and the factor "Using YouTube for self-actualization" (F5) ( $r h o=0.166 ; p=0.000)$. There is a positive correlation between the frequency of weekly YouTube use by means of a tablet and the factor "Using YouTube for self-expression" ( $F 7$ ) ( $r h o=0.113 ; p=0.010)$. There is a positive correlation between the frequency of weekly YouTube use by means of a tablet and the factor "Using YouTube to acquire reputation and become famous" (F9) (rho $=0.153 ; p=0.000$ ).

There is a positive correlation between the frequency of weekly YouTube use by means of a laptop and the factor "Using YouTube to acquire information and reach alternative information" (F1) (rho=0.135; $p=0.002$ ). There is a positive correlation between the frequency of weekly YouTube use by means of a laptop and the factor "Using YouTube to access alternative news broadcasting" (F2) $(r h o=0.192 ; p=0.000)$. There is a positive correlation between the frequency of weekly YouTube use by means of a laptop and the factor "Using YouTube for social interaction" ( $F 4)$ (rho=0.130; $p=0.002$ ). There is a positive correlation between the frequency of weekly YouTube use by means of a laptop and the factor "Using YouTube for self-actualization" (F5) (rho=0.097; $p=0.025)$. There is a positive correlation between the frequency of weekly YouTube use by means of a laptop and the factor "Using YouTube for education" (F6) (rho=0.097; $\mathrm{p}=0.024)$. There is a positive correlation between the frequency of weekly YouTube use by means of a laptop and the factor "Using YouTube for selfexpression" (F7) (rho=0.180; $\mathrm{p}=0.000)$. There is a positive correlation between the frequency of weekly YouTube use by means of a laptop and the factor "Using YouTube for entertainment" (F8) $(r h o=0.137 ; p=0.001)$. There is a positive correlation between the frequency of weekly YouTube use by means of a laptop and the factor "Using YouTube to acquire reputation and become famous" (F9) $(r h o=0.087 ; p=0.043)$. There is a positive correlation between the frequency of weekly YouTube use by means of a laptop and the factor "Using YouTube to reach customer experience" (F10) (rho=0.157; $\mathrm{p}=0.000)$.

There is a negative correlation between the frequency of weekly YouTube use by means of a desktop and the factor "Using YouTube to acquire information and reach alternative information" (F1) ( $r h o=-0.086 ; p=0.048)$. There is a positive correlation between the frequency of weekly YouTube use by means of a desktop and the factor "Using YouTube to obtain economic and social utility" (F3) $(r h o=0.166 ; p=0.000)$. There is a positive correlation between the frequency of weekly YouTube use by means of a desktop and the factor "Using YouTube for social interaction" (F4) (rho=0.108; $\mathrm{p}=0.014$ ). There is a positive correlation between the frequency of weekly YouTube use by means of a desktop and the factor "Using YouTube for self-actualization" (F5) (rho=0.216; $p=0.000)$. There is a positive correlation between the frequency of weekly YouTube use by means of a desktop and the factor "Using YouTube for self-expression" (F7) ( $r h o=0.113 ; p=0.010)$. There is a positive correlation 
between the frequency of weekly YouTube use by means of a desktop and the factor "Using YouTube to acquire reputation and become famous" (F9) (rho=0.151; $\mathrm{p}=0.001)$.

There is a positive correlation between the frequency of weekly YouTube use by means of a smart TV and the factor "Using YouTube to access alternative news broadcasting" (F2) (rho=0.088; $\mathrm{p}=0.044$ ). There is a positive correlation between the frequency of weekly YouTube use by means of a smart TV and the factor "Using YouTube to obtain economic and social utility" (F3) (rho=0.195; $\mathrm{p}=0.000$ ). There is a positive correlation between the frequency of weekly YouTube use by means of a smart TV and the factor "Using YouTube for social interaction" (F4) (rho=0.104; $p=0.017)$. There is a positive correlation between the frequency of weekly YouTube use by means of a smart TV and the factor "Using YouTube for self-actualization" (F5) ( $r h o=0.127 ; p=0.004)$. There is a positive correlation between the frequency of weekly YouTube use by means of a smart TV and the factor "Using YouTube for education" ( $F 6)$ ( $r h o=0.166 ; p=0.000)$. There is a positive correlation between the frequency of weekly YouTube use by means of a smart TV and the factor "Using YouTube for selfexpression" (F7) (rho=0.151; $\mathrm{p}=0.001$ ). There is a positive correlation between the frequency of weekly YouTube use by means of a smart TV and the factor "Using YouTube to acquire reputation and become famous" (F9) (rho=0.218; $\mathrm{p}=0.000$ ) (See Table 4).

\begin{tabular}{|c|c|c|c|c|c|c|c|c|c|c|}
\hline & $\mathrm{F} 1$ & F2 & F3 & F4 & F5 & F6 & F7 & F8 & F9 & F10 \\
\hline Mobile $\uparrow$ & $\uparrow$ & $\uparrow$ & & $\uparrow$ & & $\uparrow$ & $\uparrow$ & $\uparrow$ & $\uparrow$ & $\uparrow$ \\
\hline Tablet $\uparrow$ & & & $\uparrow$ & & $\uparrow$ & & $\uparrow$ & & $\uparrow$ & \\
\hline Laptop $\uparrow$ & $\uparrow$ & $\uparrow$ & & $\uparrow$ & $\uparrow$ & $\uparrow$ & $\uparrow$ & $\uparrow$ & $\uparrow$ & $\uparrow$ \\
\hline Desktop $\uparrow$ & $\downarrow$ & & $\uparrow$ & $\uparrow$ & $\uparrow$ & & $\uparrow$ & & $\uparrow$ & \\
\hline Smart TV $\uparrow$ & & $\uparrow$ & $\uparrow$ & $\uparrow$ & $\uparrow$ & $\uparrow$ & $\uparrow$ & & $\uparrow$ & \\
\hline
\end{tabular}

When the relationship between the communication devices and the weekly YouTube use motivations is considered, it is seen that there is a significant relationship between a laptop and the YouTube use motivations the most. There is a significant relationship with a laptop in nine of ten motivations.

According to the above-mentioned findings, the hypothesis "In the context of the uses and gratifications approach, the university students prefer mobile devices for daily and weekly YouTube use" (Hypothesis 5) was rejected.

In Hypothesis 5, it is seen that the university students did not prefer using the mobile devices that they most intensively used in their everyday life but used a laptop when using YouTube - a popular social media platform. Hence, the hypothesis "In the context of the uses and gratifications approach, the university students prefer mobile devices for daily and weekly YouTube use" (Hypothesis 5) was rejected.

There is a positive correlation between the number of channels the respondents followed on YouTube and the factor "Using YouTube to acquire information and reach alternative information" (F1) (rho=0.167; $p=0.001$ ). There is a positive correlation between the number of channels the respondents followed on YouTube and the factor "Using YouTube to access alternative news broadcasting" (F2) $(r h o=0.143 ; p=0.006)$. There is a positive correlation between the number of channels the respondents followed on YouTube and the factor "Using YouTube to obtain economic and social utility" (F3) (rho=0.157; $\mathrm{p}=0.003$ ). There is a positive correlation between the number of channels the respondents followed on YouTube and the factor "Using YouTube for social interaction" (F4) (rho=0.269; $p=0.000$ ). There is a positive correlation between the number of channels the respondents followed on YouTube and the factor "Using YouTube for education" ( $F 6)(r h o=0.190 ; p=0.000)$. There is a positive correlation between the number of channels the respondents followed on YouTube and the factor "Using YouTube for self-expression" $(F 7)(r h o=0.250 ; p=0.000)$. There is a positive correlation between the number of channels the respondents followed on YouTube and the factor "Using YouTube for entertainment" $(F 8)(r h o=0.166 ; p=0.002)$. There is a positive correlation between the 
number of channels the respondents followed on YouTube and the factor "Using YouTube to acquire reputation and become famous" $(\mathrm{F} 9)$ ( $r \mathrm{ho}=0.158 ; \mathrm{p}=0.002$ ). There is a positive correlation between the number of channels the respondents followed on YouTube and the factor "Using YouTube to reach customer experience" ( $F 10)($ rho $=0.114 ; p=0.030)$.

There is a positive correlation between the number of available followers of the respondents at their own channel on YouTube and the factor "Using YouTube to obtain economic and social utility" (F3) (rho=0.372; $\mathrm{p}=0.000$ ). There is a positive correlation between the number of available followers of the respondents at their own channel on YouTube and the factor "Using YouTube for social interaction" ( $F 4)(r h o=0.330 ; p=0.000)$. There is a positive correlation between the number of available followers of the respondents at their own channel on YouTube and the factor "Using YouTube for selfactualization" ( $F 5)$ ( $r h o=0.279 ; p=0.002)$. There is a positive correlation between the number of available followers of the respondents at their own channel on YouTube and the factor "Using YouTube for self-expression" (F7) ( $r h o=0.385 ; \mathrm{p}=0.000)$. There is a positive correlation between the number of available followers of the respondents at their own channel on YouTube and the factor "Using YouTube to acquire reputation and become famous" (F9) (rho=0.315; p=0.001) (See Table 5).

\begin{tabular}{|l|c|c|c|c|c|c|c|c|c|c|}
\hline & F1 & F2 & F3 & F4 & F5 & F6 & F7 & F8 & F9 & F10 \\
\hline $\begin{array}{l}\text { The number of channels the } \\
\text { respondents followed on YouTube } \uparrow\end{array}$ & $\uparrow$ & $\uparrow$ & $\uparrow$ & $\uparrow$ & & $\uparrow$ & $\uparrow$ & $\uparrow$ & $\uparrow$ & $\uparrow$ \\
\hline $\begin{array}{l}\text { The number of available followers of } \\
\text { the respondents at their own channel } \\
\text { on YouTube } \uparrow\end{array}$ & & & $\uparrow$ & $\uparrow$ & $\uparrow$ & & $\uparrow$ & & $\uparrow$ & \\
\hline
\end{tabular}

Table 5. The Table on the Relationships of the Number of Channels the Respondents Followed on YouTube and The Number of Followers at Their Own Channel with the Research Factors

In Table 5, it is seen that nine of ten motivations of the respondents have a significant relationship with the number of channels followed on YouTube. This shows that as the number of channels followed increases, motivations also diversify depending on the gratification obtained from its use. Additionally, it is seen that the increase in the number of followers of the respondents on YouTube has a significant relationship with five of ten motivations. This demonstrates that the number of channels followed, i.e. the motivations for using YouTube for general purposes, is related to uses to obtain more personal advantages, unlike its use to increase the number of followers.

According to the above-mentioned findings, the hypothesis "There is a linear relationship between the large number of channels followed on YouTube and the YouTube use motivations." (Hypothesis 6) was accepted. According to the above-mentioned findings, the hypothesis "There is a linear relationship between the use to increase the number of available followers on YouTube and the use for social interaction and to acquire reputation/become famous." (Hypothesis 7) was accepted.

A significant difference in the factor "Using YouTube to acquire information and reach alternative information" (F1) was detected between those who did and did not have a YouTube account (Mean Rank of those with a YouTube account=299.58; Mean Rank of those without a YouTube account=265.92; $p=0.015)$. It is seen that those with a YouTube account thought more positively about the use of YouTube to acquire information and to reach alternative information than those without a YouTube account. A significant difference in the factor "Using YouTube to access alternative news broadcasting" (F2) was detected between respondents' possessing and lacking of a YouTube account (Mean Rank of those with a YouTube account=300.19; Mean Rank of those without a YouTube account=261.99; $p=0.006$ ). It is seen that those with a YouTube account thought more positively about the use of YouTube to access alternative news broadcasting than those without a YouTube account. A significant difference in the factor "Using YouTube to obtain economic and social utility" (F3) was detected between respondents' possessing and lacking of a YouTube account (Mean Rank of those with a YouTube account $=300.88$; Mean Rank of those without a YouTube account=263.60; $p=0.007$ ). It is seen that those with a YouTube account thought more positively about the use of YouTube to obtain economic and social utility than those without a YouTube account. A significant difference in the factor "Using YouTube for social interaction" (F4) was detected between 
respondents' possessing and lacking of a YouTube account (Mean Rank of those with a YouTube account=300.09; Mean Rank of those without a YouTube account=265.00; $p=0.011$ ). It is seen that those with a YouTube account thought more positively about the use of YouTube for social interaction than those without a YouTube account. A significant difference in the factor "Using YouTube for selfexpression" (F7) was detected between respondents' possessing and lacking of a YouTube account (Mean Rank of those with a YouTube account=298.89; Mean Rank of those without a YouTube account=265.83; $p=0.019$ ). It is seen that those with a YouTube account thought more positively about the use of YouTube for self-expression than those without a YouTube account. A significant difference in the factor "Using YouTube for entertainment" (F8) was detected between respondents' possessing and lacking of a YouTube account (Mean Rank of those with a YouTube account=297.22; Mean Rank of those without a YouTube account=268.80; $p=0.044)$. It is seen that those with a YouTube account thought more positively about the use of YouTube for entertainment than those without a YouTube account. A significant difference in the factor "Using YouTube to acquire reputation and become famous" (F9) was detected between respondents' possessing and lacking of a YouTube account (Mean Rank of those with a YouTube account=297.18; Mean Rank of those without a YouTube account=268.86; $p=0.044)$. It is seen that those with a YouTube account thought more positively about the use of YouTube to acquire reputation and to become famous than those without a YouTube account. A significant difference in the factor "Using YouTube to reach customer experience" (F10) was detected between respondents' possessing and lacking of a YouTube account (Mean Rank of those with a YouTube account=300.96; Mean Rank of those without a YouTube account=263.45; $p=0.007$ ). It is seen that those with a YouTube account thought more positively about the use of YouTube to reach customer experience than those without a YouTube account.

A significant difference in the factor "Using YouTube to acquire information and reach alternative information" (F1) was detected between those who did and did not use their real name in their YouTube user account (Mean Rank of those who used their real name in their YouTube user account=267.72; Mean Rank of those who did not use their real name in their YouTube user account=219.03; $p=0.001)$. It is seen that those who used their real name in their YouTube user account thought more positively about the use of YouTube to acquire information and to reach alternative information than those who did not use their real name in their YouTube user account. A significant difference in the factor "Using YouTube to access alternative news broadcasting" (F2) was detected between those who did and did not use their real name in their YouTube user account (Mean Rank of those who used their real name in their YouTube user account=266.47; Mean Rank of those who did not use their real name in their YouTube user account=218.22; $p=0.001$ ). It is seen that those who used their real name in their YouTube user account thought more positively about the use of YouTube to access alternative news broadcasting than those who did not use their real name in their YouTube user account. A significant difference in the factor "Using YouTube for social interaction" (F4) was detected between those who did and did not use their real name in their YouTube user account (Mean Rank of those who used their real name in their YouTube user account=264.32; Mean Rank of those who did not use their real name in their YouTube user account=229.18; $p=0.014$ ). It is seen that those who used their real name in their YouTube user account thought more positively about the use of YouTube for social interaction than those who did not use their real name in their YouTube user account. A significant difference in the factor "Using YouTube for education" (F6) was detected between those who did and did not use their real name in their YouTube user account (Mean Rank of those who used their real name in their YouTube user account=265.61; Mean Rank of those who did not use their real name in their YouTube user account=220.82; $p=0.002$ ). It is seen that those who used their real name in their YouTube user account thought more positively about the use of YouTube for education than those who did not use their real name in their YouTube user account. A significant difference in the factor "Using YouTube for self-expression" (F7) was detected between those who did and did not use their real name in their YouTube user account (Mean Rank of those who used their real name in their YouTube user account $=266.21$; Mean Rank of those who did not use their real name in their YouTube user account=221.92; $p=0.002$ ). It is seen that those who used their real name in their YouTube user account thought more positively about the use of YouTube for self-expression than those who did not use their real name in their YouTube user account. A significant difference in the factor "Using YouTube for entertainment" (F8) was detected between those who did and did not use their real name in their YouTube user account (Mean Rank of those who used their real name in their YouTube user account=267.87; Mean Rank of those who did not use their real name in their YouTube user account=216.28; $\mathrm{p}=0.000$ ). It is seen that those who used their real name in their YouTube user account thought more positively about the use of YouTube for entertainment than those 
who did not use their real name in their YouTube user account. A significant difference in the factor "Using YouTube to acquire reputation and become famous" (F9) was detected between those who did and did not use their real name in their YouTube user account (Mean Rank of those who used their real name in their YouTube user account=263.85; Mean Rank of those who did not use their real name in their YouTube user account=228.37; $p=0.016$ ). It is seen that those who used their real name in their YouTube user account thought more positively about the use of YouTube to acquire reputation and to become famous than those who did not use their real name in their YouTube user account. A significant difference in the factor "Using YouTube to reach customer experience" (F10) was detected between those who did and did not use their real name in their YouTube user account (Mean Rank of those who used their real name in their YouTube user account=267.03; Mean Rank of those who did not use their real name in their YouTube user account=221.10; $p=0.002)$. It is seen that those who used their real name in their YouTube user account thought more positively about the use of YouTube to reach customer experience than those who did not use their real name in their YouTube user account (See Table 6).

\begin{tabular}{|l|c|c|c|c|c|c|c|c|c|c|}
\hline & $\mathrm{F} 1$ & $\mathrm{~F} 2$ & $\mathrm{F3}$ & $\mathrm{F} 4$ & $\mathrm{~F} 5$ & $\mathrm{F6}$ & $\mathrm{F7}$ & $\mathrm{F} 8$ & $\mathrm{F9}$ & $\mathrm{F} 10$ \\
\hline $\begin{array}{l}\text { Those with a YouTube } \\
\text { account }\end{array}$ & $\mathrm{X}$ & $\mathrm{X}$ & $\mathrm{X}$ & $\mathrm{X}$ & & & $\mathrm{X}$ & $\mathrm{X}$ & $\mathrm{X}$ & $\mathrm{X}$ \\
\hline $\begin{array}{l}\text { Those who used their real } \\
\text { name in their YouTube } \\
\text { account }\end{array}$ & $\mathrm{X}$ & $\mathrm{X}$ & & $\mathrm{X}$ & & $\mathrm{X}$ & $\mathrm{X}$ & $\mathrm{X}$ & $\mathrm{X}$ & $\mathrm{X}$ \\
\hline
\end{tabular}

Table 6. The Table Which Shows Whether There is a Difference Between Those with a YouTube Account and Those Who Used Their Real Name in Their YouTube Account and the Research Factors.

In Table 6, it is seen that those with a YouTube account and those who used their real name in their YouTube account did not use YouTube for self-actualization (F5). In summary, no difference in F5 occurred between the two research questions. Again, in Table 6, it is seen that the respondents with a YouTube account did not tend to use YouTube for education (F6). Moreover, it is seen that those who used their real name in their account did not use YouTube to obtain economic and social utility (F3).

According to the above-mentioned findings, the hypothesis "Users' possessing of a YouTube account affects their YouTube use motivations." (Hypothesis 8) was accepted.

It is seen that possessing a YouTube account was not effective on the motivations for use for self-actualization (F5) and education (F6). It is seen that possessing a YouTube account created a significant difference in the other use motivations.

According to the above-mentioned findings, the hypothesis "Users' use of their real name in their YouTube account affects their YouTube use motivations." (Hypothesis 9) was accepted.

It is seen that users' use of their real name in their YouTube account was not effective on the motivations for use for self-actualization (F5) and to obtain economic and social utility (F3). It is seen that those who used their real name in their YouTube account created a significant difference in the other use motivations.

\section{Conclusion}

Upon Klapper's questioning of "what the audience do with the media" in 1963, the approach that media consumption took place within consumers' consciousness was acknowledged and it was discovered that the audience inclined to the media in line with their needs. The relationship of the young people of university age with the media - the subject of this research - varies between acquiring information and entertainment as well as between social interaction and self-development or self-actualization. The most discovered finding in the studies carried out on different social media platforms with the uses and gratifications approach is that the most important factors determining the gratification obtained from social media use are socialization/acquisition of a social environment and entertainment. 
In this study, which addresses to what extent the young people of university age were influenced by virtual interaction specifically on YouTube in the context of the uses and gratifications approach, it is seen that the university students used YouTube to acquire information and reach alternative information, to access alternative news broadcasting, to obtain economic and social utility, for social interaction, for self-actualization, for education, for self-expression, for entertainment, to acquire reputation and become famous, and to reach customer experience, respectively. It turned out that the university students used YouTube by means of a mobile device on each day of the week and for an hour to 3 hours (an hour to 2 hours and $59 \mathrm{~min}$ ) per day in order to acquire information and to access alternative information. A laptop was determined to be the communication device which enhanced the use motivations the most. This demonstrates that they prefer a laptop when the use motivations have increased, whereas they prefer accessing YouTube by means of mobile devices in the everyday use with limited motivations.

It is seen that the more the motivations of users are, the greater their need to use YouTube becomes. This reveals the significance of the interaction among the use motivations. In connection with this result, the large number of channels followed on YouTube and the abundance of use motivations develop in the same line. Another result obtained from the research is that those with a YouTube account did not use YouTube for self-actualization or for education. Likely to be performed anonymously, such needs were not preferred much by those with a YouTube account. A similar result also applies to the users who used their real name in their account. These users did not prefer using YouTube for self-actualization or to obtain economic and social utility either.

The findings reached differ from the results of the studies carried out for various social media platforms with the uses and gratifications approach. Established with the slogan "Your Digital Video Repository", YouTube adopted the slogan "Broadcast Yourself" over time, thereby intending to bring the factors of social interaction and entertainment - which are of high priority in the use of the other social media platforms - to the forefront. Nevertheless, the factor of acquiring information ranked first among the use motivations as a result of the research, which demonstrates that YouTube is used as an alternative to the search engines to reach information particularly by the university youth.

\section{References}

[1] Akçay, H. (2011). Kullanımlar ve Doyumlar Yaklaşımı Bağlamında Sosyal Medya Kullanımı: Gümüşhane Üniversitesi Üzerine Bir Araştırma. İletişim Kuram ve Araştırma Dergisi, 33, 137161.

[2] Akyıldız, M. and Argan, M. (2015). Leisure Experience Tagged On Facebook: The Influence of Facebook Experiences On Satisfaction. Pamukkale Journal of Sport Sciences, 6(2), 46-64.

[3] Alikılıç, Ö., Gülay, G. and Binbir, S. (2013). Kullanımlar ve Doyumlar Kuramı Çerçevesinde Facebook Uygulamalarının İncelenmesi: Yaşar Üniversitesi Öğrencileri Üzerine Bir Araştırma. İletişim Kuram ve Araştırma Dergisi, 37, 40-67.

[4] Aydın, M. and Çelik, T. (2017). Sosyal Bilgiler Öğretmen Adaylarının Sosyal Medya Kullanım ve Doyumlarının İncelenmesi. Eğitim Kuram ve Uygulama Araştırmaları Dergisi, 3(2), 82-97.

[5] Ayhan, B. and Çavuş, S. (2014). İzleyici Araştırmalarında Değişim: Kullanımlar ve Doyumlardan Bağımlıı̆a. Selçuk Üniversitesi İletişim Fakültesi Akademik Dergisi, 8(2), 32-60.

[6] Balcı, Ş. and Ayhan, B. (2007). Üniversite Öğrencilerinin İnternet Kullanım ve Doyumları Üzerine Bir Saha Araştırması. Selçuk İletişim, 5(1), 174-197.

[7] Bonander, A. R. and Marsh, M. L. (2015). Modern Mimicry and YouTube: How Technology Has Influenced Pedagogy and Performance of Poetry Interpretation Within Competitive Forensics. Communication Studies, 66(4), 448-457.

[8] Bonds-Raacke, J. and Raacke, J. (2010). MySpace and Facebook: Identifying Dimensions of Uses and Gratifications for Friend Networking Sites. Individual Differences Research, 8(1), 2733.

[9] Burgess, J. and Green, J. (2010). YouTube Online Video and Participatory Culture, Cambridge, UK: Polity Press. 
[10] Çalışır, G. (2015). Kişilerarası İletişimde Kullanılan Bir Araç Olarak Sosyal Medya: Gümüşhane Üniversitesi İletişim Fakültesi Öğrencilerine Yönelik Bir Araştırma. Humanities Science, 10(3), 115-144.

[11] ebizMBA (2018). Top 15 Most Popular Social Networking Sites, May 2018. http://www.ebizmba.com/articles/social-networking-websites Date of Access: 04.02.2018.

[12] Erdoğan, İ. and Alemdar, K. (2002). Öteki kuram. Ankara: Erk Yayınları.

[13] Erol, G. and Hassan, A. (2014). Gençlerin Sosyal Medya Kullanımı ve Sosyal Medya Kullanımının Tatil Tercihlerine Etkisi. Uluslararası Sosyal Araştırmalar Dergisi, 7(31), 804-812.

[14] Güngör, N. (2013). İletişim: Kuramlar ve Yaklaşımlar. Ankara: Siyasal Kitabevi.

[15] Haridakis, P. and Hanson, G. (2009). Social Interaction and Co-Viewing With YouTube: Blending Mass Communication Reception and Social Connection. Journal of Broadcasting \& Electronic Media, 53(2), 317-335.

[16] Hazar, Ç. M. (2011). Sosyal Medya Bağımlıı̆ı-Bir Alan Çalışması. Iletişim Kuram ve Araştırma Dergisi, Bahar 2011, 32, 151-176.

[17] Hussain, F. (2015). YouTube. In F.F. Wherry, The SAGE Encyclopedia of Economics and Society (p. 1740-1742). London: SAGE Publications.

[18] IAB Türkiye (2017). Türkiye İnternet Ölçümleme Araştırması. https://www.iabturkiye.org/UploadFiles/TopTwentyFiles/Internet_audience_toplist_07_2017_Ov ernight.pdf Date of Access: 04.02.2018.

[19] Ignite Social Media (2017). How Social Media Changed in 2017. https://www.ignitesocialmedia.com/social-media-marketing/social-media-changed-2017/ Date of Access: 04.02.2018.

[20] Ignite SocialMedia (2011). Social Network Analysis Data. https://s3.amazonaws.com/ignitesma/ignitewebsite/2011-social-network-analysis.pdf Date of Access: 10.12.2017.

[21] Kara, T. (2016). Gençler Neden Snapchat Kullanıyor? Kullanımlar ve Doyumlar Yaklaşımı Üzerinden Bir Araştırma. Intermedia International e-Journal, Fall, December, 3(5), 262-277.

[22] Karadağ, G. H. (2017). Reporting and Interviewing Styles of Professional and Citizen Reporters on Periscope. Communication and Technology Congress (CTC 2017), 88-104.

[23] Katz, E., Blumler, J. G. and Gurevitch, M. (1974). The Uses and Gratifications Approach to Mass Communication. Beverly Hills, California: SAGE Publications.

[24] Kemp, S. (2017). Digital in 2017 Global Overview. https://wearesocial.com/specialreports/digital-in-2017-global-overview Date of Access: 26.03.2018.

[25] Khan, M. L. (2017). Social Media Engagement: What Motivates User Participation and Consumption on YouTube? Computers in Human Behavior, 66, 236-247.

[26] Koçak, N. G. (2012). Bireylerin Sosyal Medya Kullanım Davranışlarının ve Motivasyonlarının Kullanımlar ve Doyumlar Yaklaşımı Bağlamında İncelenmesi: Eskişehir'de Bir Uygulama. Basılmamış Doktora Tezi, Anadolu Üniversitesi Halkla İlişkiler ve Reklamcılık A.B.D., Eskişehir.

[27] Küçükkurt, M., Hazar, Ç. M., Çetin, M. and Topbaş, H. (2009). Kullanımlar ve Doyumlar Yaklaşımı Perspektifinden Üniversite Öğrencilerinin Medyaya Bakışı. Selçuk İletişim Dergisi, 6(1), 37-50.

[28] McQuail, D. (1987). Mass Communication Theory: An Introduction (2nd edn.). London: Sage Publications.

[29] Özer, Ö. (2017). Kullanımlar ve Doyumlar Kuramı Çerçevesinde Eskişehir Osmangazi Üniversitesi İ̈BF Öğrencilerinin Twitter Kullanımı Üzerine Bir Analiz. Intermedia International Peer-Reviewed E-Journal of Communication Sciences, 4(6), 40-58.

[30] Papacharissi, Z. and Rubin, A. M. (2000). Predictors of Internet Use. Journal of Broadcasting \& Electronic Media, 44(2), 175-196.

[31] Pempek, T. A., Yermolayeva, Y. A. and Calvert, S. L. (2009). College Students' Social Networking Experiences on Facebook. Journal of Applied Development Psychology, 30, 227 238.

[32] Rubin, A. M. and Bantz, C. R. (1987). Utility of Videocassette Recorders, American Behavioral Scientist, 30(5), 471-485. 
[33] Sherry, J., Lucas, K., Greenberg, B. and Lachlan, K., (2006). Video Game Uses and Gratifications as Predictors of Use and Game Preference In Playing Video Games: Motives, Responses, and Consequences (Compiled by) P. Vorderer \& J. Bryant Mahwah, NJ, Lawrence Erlbaum Associates, 213-224.

[34] Solmaz, B., Tekin, G., Herzem, Z. and Demir, M. (2013). İnternet ve Sosyal Medya Kullanımı Üzerine Bir Uygulama. Selçuk Üniversitesi İletişim Fakültesi Akademik Dergisi, 7(4), 23-32.

[35] Thorson, K., Driscoll, K., Ekdale, B., Edgerly, S., Thompson, L. G., Schrock, A., Swartz, L., Vraga, E. K. and Wells, C. (2013). Youtube, Twitter and The Occupy Movement. Information, Communication \& Society, 16(3), 421-451.

[36] Vural, Z. B. A. and Bat, M. (2010). Yeni Bir Illetişim Ortamı Olarak Sosyal Medya: Ege Üniversitesi İletişim Fakültesine Yönelik Bir Araştırma. Journal of Yaşar University, 5(20), 33483382.

[37] Wang, T.-L. (2014). The Usage Behaviors, Motivations and Gratifications of Using UserGenerated Media: The Case Study of Taiwan's YouTube. Advances in Journalism and Communication, 2, 137-150.

[38] Whiting, A. and Williams, D. (2013). Why People Use Social Media: A Uses and Gratifications Approach. Qualitative Market Research: An International Journal, 16(4), 362-369.

[39] Yılmaz, S. S. (2016). Medya Güvenilirliği: Gençlerin Medya Güvenilirliği Üzerine Ampirik Bir Çalışma. Gümüşhane Üniversitesi İletişim Fakültesi Elektronik Dergisi e-GiFDER, 4(1), 392417.

[40] YouTube (2018a). https://www.youtube.com/int//tr/yt/impactlab/why-youtube/ Date of Access: 26.03.2018.

[41] YouTube (2018b). https://creatoracademy.youtube.com/page/lesson/discovery?hl=tr\#strategieszippy-link-7 Date of Access: 07.09.2018. 